\title{
Operative Management and Disposal of Hospital Wastes: A Comprehensive Appraisal
}

\author{
Hindustan Abdul Ahad (iD ${ }^{1,}$, Lami Singh $^{1}$, Haranath Chinthaginjala ${ }^{1}$, Sravya Nandyala Nandyala ${ }^{1}$, \\ Reddy Haritha ${ }^{1}$ and Akhila Chowdary ${ }^{1}$ \\ ${ }^{1}$ Department of Industrial Pharmacy, Raghavendra Institute of Pharmaceutical Education and Research (RIPER), KR Palli Cross-515721, Ananthapuramu, Andhra Pradesh, India \\ "Corresponding author: Department of Industrial Pharmacy, Raghavendra Institute of Pharmaceutical Education and Research (RIPER), KR Palli Cross-515721, Ananthapuramu, \\ Andhra Pradesh, India. Email: abdulhindustan@gmail.com
}

Received 2021 March 08; Revised 2021 August 10; Accepted 2021 August 22.

\begin{abstract}
Health clinics are significant destinations for the creation of risky waste. Every clinic has its own profile for the management and transport of waste contingent upon its area. It is amazingly crucial to guarantee that the waste created in medical clinics is sufficiently kept away from dangers to well-being and the climate. The manuscript describes the control of clinical waste, which incorporates infectious waste, synthetic substances, lapsed medications, radioactive trash, and rough waste are the major ones in hospitals. On the off chance that the administration is not efficient, it becomes perilous, as they are pathogenic and environmentally unsafe. Inability to do so can bring about negative results; for example, genuine well-being chances and the clinic's standing. This article portrays the different ways to deal with the powerful administration of clinic squander. The authors conclude that pretreatment is basic before discarding emergency clinic squander in a hospital to minimize hazardous issues.
\end{abstract}

Keywords: Hospital, Pathogenic, Waste, Environment

\section{Context}

The hospital is a fundamental site for the creation of waste. Every hospital office creates squander, and the item overall is a misuse of various kinds, sterile, homegrown, and authoritative (1). The specific clinical waste like disposing of wound dressings, expired synthetic substances/drugs, radioactive materials, and rough materials (needles, surgical blades, scissors, and so on). Since these materials cause pathogenic and natural calamities, they should be treated efficiently (2).

Individuals who work in medical care and scroungers when presented with this waste because of microbial contamination. Ill-advised treatment of sharp articles can cause the needle to leave wounds and lead to contamination with blood-borne microbes (3).

Untreated waste causes cerebral pains, dazedness, sickness, tissue harm, fetal neoplasms and distortions, heart, and respiratory infections (4).

The administration of waste produced by hospitals is the obligation of hospital workers and everybody in every division. The development of dangerous clinical waste should be all around constrained by its creation, treatment, and removal (5).

The main foundations of healthcare waste are blood banks, clinics, pre-clinical and clinical labs, mortuary/autopsy centers, and nursing homes. We aimed to give information to follow and adapt to maintain cleanliness and hygiene in the hospital.

\section{The Rules on Waste in India}

India planned the rules on the organization and treatment of bio-medical waste (BMW) in 1998 and amended them in 2016. The rules enclosed by the Central Pollution Control Board (CPCB) to aid in the execution of the rubrics: (1) strategies for the supervision of BMW management in 1998; (2) recommendations for the Common Bio-medical Waste Treatment Facility (CBWTF); (3) plan and building of BMW incinerator.

\section{Steps Involved in Hospital Waste Management}

There are various measures in the hospital's organization waste as follows (6): (1) training and awareness, (2) generation, (3) separation, (4) collection, (5) transportation, (6) storage, (7) treatment, (8) final disposal.

The WHO has recommended a color code for the respective waste bins (Table 1 and Figure 1) (7). 


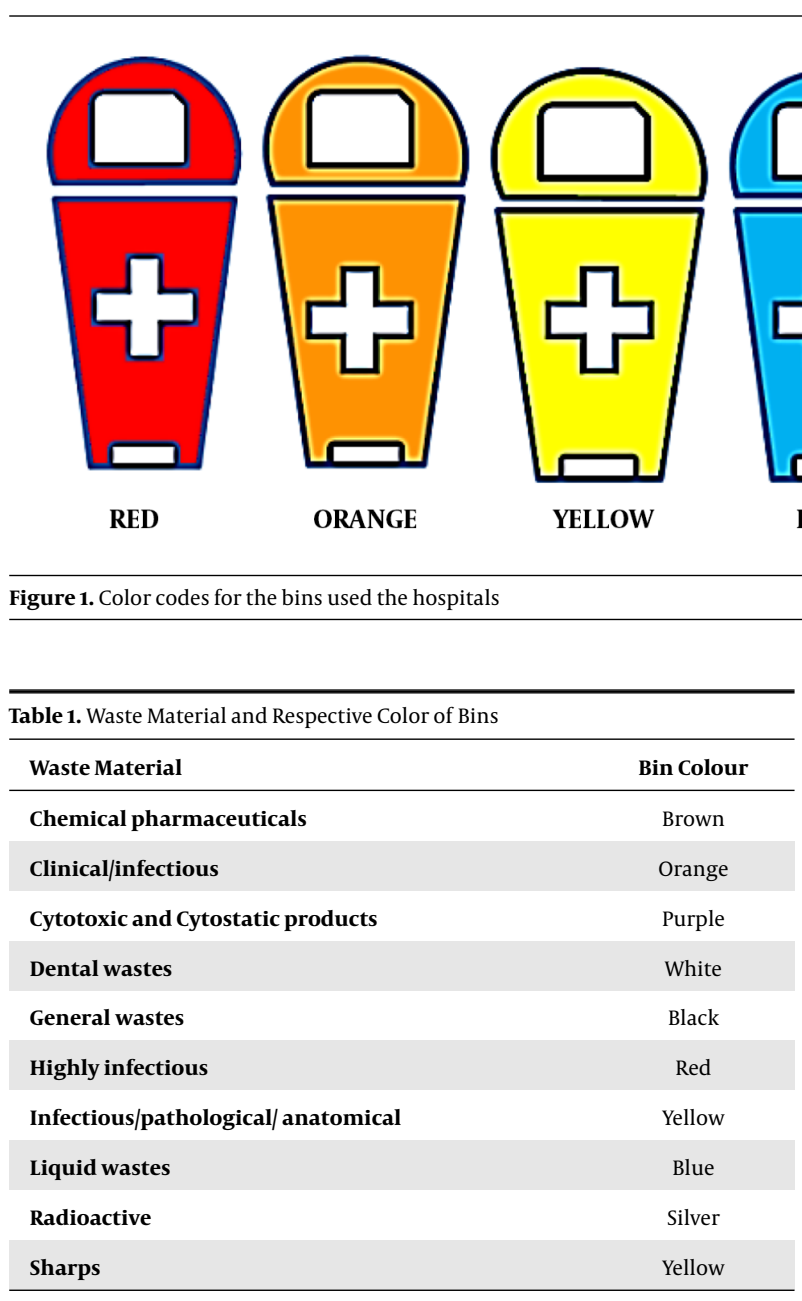

The waste collectors should wear protective gloves, collect and segregate the waste materials into colored bags/bins. These bags should be zipped tightly around the neck.

\section{Final Discarding Methods}

Finally, the collected waste has been discarded by the process of incineration (at $>1200^{\circ} \mathrm{C}$ ), chemical disinfection, or by rendering it inert. The various strategies and categories of waste disposal in the hospital are as follows.

\subsection{General and Harmful Waste}

According to the set of laws for industrial waste, hospital waste should not be added to a sewage line. For example, sugar, lactic acid, bromides, or carbonates. Even though they do not adversely harm human health, they must be first collected, accumulated, treated, and dumped in secured landfills (8).

\subsection{Liquid Waste}

They should be treated with a chemical disinfectant, neutralized, and discarded into the sewage. The liquid waste oriented from hospitals is of the following types (9).

\subsection{Contagious Waste}

These include blood, body fluids, laboratory wastes (cultures of contagious microbes, eliminated vaccines, culture dishes, etc.) (10).

Autoclaving and securing culture media in autoclavable bags can ensure that media in Petri dishes are free from microorganisms. Again, the bags are sterilized and passed on to micro waste containers that are disposed of in municipal trash or incinerated.

Currently, there are no new methods available, the same approaches are used, but they need to be strictly monitored and analyzed. Dispose of dirty and unpolluted glassware, and sterilize contaminated broken glassware. Incineration or industrial waste disposal is used to dispose of these materials. Uncontaminated glassware from urban waste can be disposed of.

\subsection{Chemically Dangerous Materials}

These forms are as follows (11,12): (1) formaldehyde (got from pathology labs, autopsy, dialysis, and embalming); (2) mercury (damaged thermometers, sphygmomanometers, and dental amalgams); (3) solvents (organic solvents from pathology and embalming); (4) radioactive isotopes (F18, Ga67, Kr81, Ru82, N13, Te99, In111, I123, Xe133, and Th201).

\subsection{Pharmaceutical Liquid Waste}

These forms of disposal contain unused/expired medications like chemicals used in photography (fixer and developer) and water after cleaning/washing hospital materials/instruments left in the drain. The liquid waste comprises either emancipation from health care amenities 
(HCF) or from household, commercial layouts, industry, and agricultural lands, which cover an extensive variety of growing contaminants and microbes. Sewage is a section of waste that has been polluted with feces and urine (13).

\subsection{Human Anatomical Waste}

Pathological and bodily wastes comprise almost everything from laboratory cultures and pileups of donated blood to tissue biopsied for testing/diagnosis/removed owing to ailments (14). These are a sub-category of pathological waste, those materials that are noticeably human such as a removed limb. Even with an effective septic scheme and a sufficient sewage treatment system, some pathological waste can be disposed of in the drain.

Wastes, like placentas from mothers after delivery and expired blood, may not be infectious, but their status is recognized. Sometimes, the amputated limbs are buried or cremated in a similar pattern as a dead person (15). Blood and placentas are necessarily disposed of in the cesspits using a macerator. This material must be first autoclaved as a preventive measure before it is further re-processed for disposal.

Bio-digestion is a present technology that has been adopted for treating such pathological wastes. However, this technique needs a long time to destroy all pathogens and guarantees that the slurry has been dealt with well. This slurry should not be used as fertilizer later.

\subsection{Abrasive Metallic Waste}

These are biomedical waste, which comprises any device/object used to puncture/lacerate the skin. Sharp waste has been considered bio-hazardous and should be handled cautiously.

Extreme attention must be paid to the removal and control of sharp wastes, as they must be carefully handled until they can be suitably discarded. The last step in disposing of sharps is by burning or autoclaving $(16,17)$.

There is a risk of injuries and infections associated with improper disposal of needles and syringes, as well as potential for reuse. Recent efforts to reduce reuse of injection devices have helped significantly reduce injections with contaminated needles and syringes in low- and middleincome countries. In addition, a hazard may arise during scavenging and during the manual sorting of hazardous waste at health care facilities. The practice is widespread in many parts of the world, especially in parts of the world with low and middle incomes. Those who handle waste are at risk of needle stick injuries and being exposed to potentially harmful substances.

\subsection{Microbiology Wastes}

The microbial wastes in the culture media of glass Petri plates must be sterilized by autoclaving and then repacked in autoclaving bags. Later, these bags are re-sterilized by autoclaving and then moved to micro-waste, which is then discarded either by incineration or municipal trash (18).

\subsection{Radioactive Waste}

If the removal of radioactive waste has not been managed and planned properly, it could lead to a drastic environmental disaster. Solid waste is discarded by accumulating and storing it, which is a trending approach for nuclear waste disposal. The storage should be done in steel or lead cylinders as a radioactive shield (19).

Hospitals use sealed sources for a variety of applications, such as teletherapy, brachytherapy, blood irradiation, and calibration. With the exception of the teletherapy and blood irradiation sources, those having high activity levels are generally relatively small. A source must be replaced once it becomes incapable of supporting future applications. To make sure that the sealed radioactive sources are safely removed and replaced, hospitals must enter into a contract with the suppliers. To order such equipment and the source, a hospital's Radiation Safety Officer should be consulted.

\section{Novel Approaches to Disposal}

The latest approaches to cleaning and destroying pathogenic waste (20-22) are summarized in Table 2.

\section{Better Practices for Hospital Waste Management}

Remedial waste is hazardous, spreadable, toxic, and even lethal to humankind. If these materials are not correctly disposed of, treated, they lead to health disasters for humans and the environment (23). Problems like disease spread, ecological poisoning, and contamination result. To ensure safe and protective management of medical waste, the following practices should be adopted.

\subsection{Keep a Check of State Rules and Regulations}

The protocol for the disposal of hospital waste was set by country/state rules. These rules help maintain and manage hospital waste creating a healthy environment as well as keeping up and keeping the medical facility constructed (24). These rules will keep organizations accredited with training, courses, and other possessions to bring awareness among people about executing proper waste management. 


\begin{tabular}{|c|c|}
\hline Waste Material to Be Treated & Approach Adopted \\
\hline $\begin{array}{l}\text { Pathological waste, infectious, plastic, hazardous chemicals, or } \\
\text { pharmaceutical waste }\end{array}$ & $\begin{array}{l}\text { Plasma pyrolysis by plasma torches/electrodes (use of ionized gas to convert } \\
\text { electrical energy to thermal energy) }\end{array}$ \\
\hline Microbes & Ozonation \\
\hline Dead bodies and parts before entombment & Freeze drying in liquid nitrogen and automated shaking \\
\hline Body parts, specimens, and cadavers & Alkaline hydrolysis \\
\hline Infectious bones and teeth & Alkali solution at $>127^{\circ} \mathrm{C}$ \\
\hline Cleaning environmental air & Nano formulation of hydroxyl species and superoxide anion $\left(\mathrm{O}^{2-}\right)$ \\
\hline Sludge water separation & Membrane bioreactors \\
\hline Wastewater treatment & Photocatalysis \\
\hline $\begin{array}{l}\text { Cultures, materials filthy with blood and fluids, laboratory waste, and } \\
\text { medical instruments }\end{array}$ & Pre-vacuum autoclaves $\left(121^{\circ} \mathrm{C}\right.$ for $30 \mathrm{~min}$, pressure of $\left.205 \mathrm{kPa}\right)$ \\
\hline Reducing the volume & multiple-shaft shredders which cut volumes $<80 \%$ \\
\hline $\begin{array}{l}\text { Culture media, blades, things tainted with blood and body fluids, other } \\
\text { diseased left-overs, laboratory leftovers, and soft waste (e.g., gauze, } \\
\text { bandages, gowns, and bedding). }\end{array}$ & $\begin{array}{l}\text { Microwave oven ( } 30 \text { cycles per min for } 1 \mathrm{~h} \text { ) Confirmed by biological indicators } \\
\text { Bacillus atrophaeus spores' vials/strips with at least } 104 \text { spores. }\end{array}$ \\
\hline Glassware and other reusable instruments & $\begin{array}{l}\text { Hot air oven (up to } 185^{\circ} \mathrm{C} \text { for } 90-150 \text { min. cleaning confirmed by the spores of } \\
\text { Geobacillus stearothermophilus or Bacillus atrophaeus with at least log106 } \\
\text { spores per ml/indicator strip }\end{array}$ \\
\hline Bacteria, viruses, and spores & 1-12\% Sodium hypochlorite ( $\mathrm{NaOCl})$ \\
\hline Disinfecting instruments & Calcium hydroxide, Glutaraldehyde, and peracetic acid are used \\
\hline Inorganic, incombustible matter & Incineration $\left(600^{\circ} \mathrm{C}\right.$ to $\left.>1,000^{\circ} \mathrm{C}\right)$ \\
\hline
\end{tabular}

\subsection{Color Code Containers and Waste Bins}

Hospital waste is broadly characterized into multiple types, and each type needs a specific disposal method. Filtering the various medical waste ensures each type was discarded, disposed of, elated, and devastated precisely, and so on (25). Color coding helps stop deadly health issues arising from mislabeled medical healthcare waste.

\subsection{Monitor and Regulate Waste}

Evaluate the success of the waste disposal and management system with a monitoring tool that easily guesses the workflow. Conducting regular inspections periodically throughout the waste management process, from filtration and gathering to storage, conveyance, and disposal (26-28).

The practices to safeguard proper waste supervision in hospitals are summarized as below: (1) it minimizes the spread of infections and reduces the risk of unintentional injury to staff, patients, and visitors, and the community; (2) it reduces the probability of infection of the soil or groundwater with chemicals or microbes; (3) it attracts fewer insects and rodents that are not attractive to animals; (4) it helps create a healthy environment.

\section{Monitoring of Waste in Hospitals}

Monitoring is a continuous and never-ending process. State pollution control boards (SPCBs), monitor and manage BMW. The Ministry of Environment, Forest, and Climate Change (MOEFCC) examines the rules through district, state, and central authorities. In hospitals, the waste management committee watches and controls the BMW.

\section{Infringement}

Any violation of the rules, healthcare facilities, and CBWTFs are answerable as per sections 5 and 15 of the environment protection act. Hospitals that cannot keep up with BMW will be punished and penalized (29).

\section{Records}

Healthcare facilities were required to keep up records of the generation, gathering, treatment, packing, conveyance, treatment, removal, or any other form of control of BMW for five years. The central or state pollution control boards and MOEFCC regularly verify these documents. 


\section{Conclusions}

Proper training, regulation, and devoted infrastructure help in the effective management of hospital waste disposal. These safeguard precautions and effective disposal protect hospital staff, patients, the public, and the environment, which provides a clean and safe environment. The novel approach to the waste management system in treating hospital waste and disposal as per the color codes of the bins is simple and effective in identification and disposal of waste in hospitals. Still, a proper plan, protocol, and research are required for the effective disposal of waste for hospitals to give a hygienic and healthy life to the globe.

\section{Footnotes}

Authors' Contribution: Study concept and design, HAA and LS; Acquisition of the data, $\mathrm{CH}$ and NS; Drafting of the manuscript, RH; Critical revision of the manuscript for important intellectual content, PAC and HAA.

Conflict of Interests: The authors declare no conflict of interest.

\section{Funding/Support: There was no funding/support.}

\section{References}

1. Cheng YW, Li KC, Sung FC. Medical waste generation in selected clinical facilities in Taiwan. Waste Manag. 2010;30(8-9):1690-5. doi 10.1016/j.wasman.2010.04.006. [PubMed: 20427173].

2. Sozzi E, Fabre K, Fesselet JF, Ebdon JE, Taylor H. Minimizing the risk of disease transmission in emergency settings: Novel in situ physicochemical disinfection of pathogen-laden hospital wastewaters. PLoS Negl Trop Dis. 2015;9(6). e0003776. doi: 10.1371/journal.pntd.0003776. [PubMed: 26110821]. [PubMed Central: PMC4482504].

3. Bekele T, Gebremariam A, Kaso M, Ahmed K. Factors associated with occupational needle stick and sharps injuries among hospital healthcare workers in Bale Zone, Southeast Ethiopia. PLoS One. 2015;10(10). e0140382. doi: 10.1371/journal.pone.0140382. [PubMed: 26469776] [PubMed Central: PMC4607483]

4. Ghorani-Azam A, Riahi-Zanjani B, Balali-Mood M. Effects of air pollution on human health and practical measures for prevention in Iran. J Res Med Sci. 2016;21:65. doi: 10.4103/1735-1995.189646. [PubMed: 27904610]. [PubMed Central: PMC5122104].

5. Khadem Ghasemi M, Mohd Yusuff R. Advantages and disadvantages of healthcare waste treatment and disposal alternatives: Malaysian scenario. Pol J Environ Stud. 2016;25(1):17-25. doi: 10.15244/pjoes/59322.

6. Aung TS, Luan S, Xu Q. Application of multi-criteria-decision approach for the analysis of medical waste management systems in Myanmar. J Clean Prod. 2019;222:733-45. doi:10.1016/j.jclepro.2019.03.049.

7. World Health Organization. Interim infection prevention and control guidance for care of patients with suspected or confirmed filovirus haemorrhagic fever in health-care settings, with focus on Ebola. Geneva, Switzerland: World Health Organization; 2014.

8. Ferdowsi A, Ferdosi M, Mehrani Z, Narenjkar P. Certain hospital waste management practices in Isfahan, Iran. Int J Prev Med. 2012;3(Suppl 1):S176-85. [PubMed: 22826762]. [PubMed Central: PMC3399314].
9. Sancho M, Arnal JM, García-Fayos B. Treatment of hospital radioactive liquid wastes from RIA (radioimmunoassay) by membrane technology. Desalination. 2013;321:110-8. doi: 10.1016/j.desal.2013.03.032.

10. Zamparas M, Kapsalis VC, Kyriakopoulos GL, Aravossis KG, Kanteraki AE, Vantarakis A, et al. Medical waste management and environmental assessment in the Rio University Hospital, Western Greece. Sustain Chem Pharm. 2019;13:100163. doi: 10.1016/j.scp.2019.100163.

11. Arshad N, Nayyar S, Amin F, Tahir Mahmood K. Hospital waste disposal: A review article. Int J Pharm Sci Res. 2011;3(8):1412.

12. Mathur P, Patan S, Shobhawat AS. Need of biomedical waste management system in hospitals - an emerging issue - a review. Curr World Environ. 2012;7(1):117-24. doi:10.12944/cwe.7.1.18.

13. Dufour A, Bartram J, Bos R, Gannon V. Animal waste, water quality and human health. 12. London, UK: IWA Publishing; 2013. doi: 10.2166/9781780401249.

14. Qadir S, Akhtar MN, Hassan M, Ahmad I, Naeem H, Rehman O. Study of hospital waste disposal practice in a tertiary care hospital. Gomal J Med Sci. 2014;12(2).

15. Alemayehu T, Worku A, Assefa N. Community risk perception on healthcare wastes in hospitals and health centres of Eastern Ethiopia. Science Journal of Public Health. 2015;3(1):37. doi: 10.11648/j.sjph.20150301.17.

16. Mahinroosta M, Allahverdi A. Hazardous aluminum dross characterization and recycling strategies: A critical review. J Environ Manage. 2018;223:452-68. doi: 10.1016/j.jenvman.2018.06.068. [PubMed: 29957419].

17. LaGrega MD, Buckingham PL, Evans JC. Hazardous waste management. Illinois, USA: Waveland Press; 2010.

18. Tabrizi JS, Rezapour R, Saadati M, Seifi S, Amini B, Varmazyar F. Medical waste management in community health centers. Iran J Public Health. 2018;47(2):286-91. [PubMed: 29445640]. [PubMed Central: PMC5810393]

19. Su E, Chen YT. Policy or income to affect the generation of medical wastes: An application of environmental Kuznets curve by using Taiwan as an example. J Clean Prod. 2018;188:489-96. doi: 10.1016/j.jclepro.2018.04.011.

20. Pal P. Treatment and disposal of pharmaceutical wastewater: Toward the sustainable strategy. Sep Purif Rev. 2017;47(3):179-98. doi: 10.1080/15422119.2017.1354888.

21. Hamer G. Solid waste treatment and disposal: Effects on public health and environmental safety. Biotechnol Adv.2003;22(1-2):71-9. doi: 10.1016/j.biotechadv.2003.08.007. [PubMed: 14623044].

22. Wilson J, Weber P, Kaye G, McKee R, Jones W. Method and apparatus for treatment and disposal of waste material. Google Patents; 2007.

23. Mukhtar S, Khan H, Kiani Z, Nawaz S, Zulfiqar S, Tabassum N. Hospital waste management: Execution in Pakistan and environmental concerns - a review. Environ Contam Rev. 2018;1(1):18-23. doi: 10.26480/ecr.01.2018.18.23.

24. Saad SA. Management of hospitals solid waste in Khartoum State. Environ Monit Assess. 2013;185(10):8567-82. doi: 10.1007/s10661-013-3196-1. [PubMed: 23644667].

25. Fatima SZ, Asad M. Disposal of hospital wastage in Pakistan: A qualitative research. Adv Soc Sci Res. 2018;5(3). doi: 10.14738/assrj.53.4197.

26. Shettennavar S, Vithayathil A. Exploratory study of biomedical waste management-an IoT perspective. Asian J Manag. 2019;10(3):181. doi: 10.5958/2321-5763.2019.00029.5.

27. Yanik CNF, Wahyuni D, Rokhmah D. Cleaning officers' behavior in waste management according to the standards of accreditation in X Jember Hospital. Health Notions. 2019;3(1):44-51. doi: 10.33846/hn.v3i1.251

28. Sobrinho EM, Almeida AC, Colen F, Brandi IV, Duarte ER, Santos HO, et al. [Energetic potential of the use of solid wastes from laboratory animal care facilities for the production of biogas]. Acta Veterinaria Brasilica. 2012;6(1):35-9. Portuguese.

29. Gupta AK, Goel S, Talati S. Hospitals and Laws of the Land. In: Goel S, editor. Textbook of Hospital Administration. Amsterdam: Elsevier Health Sciences; 2014. 393 p. 